\title{
Study on Performance and Exhaust Gas Characteristics of Directly Injected CNG Engine
}

\author{
S. W. Lee ${ }^{1}$, Doo-Sung Baik ${ }^{2 \star}$, T. Rogers ${ }^{3}$ and P. Petersen ${ }^{4}$ \\ ${ }^{1}$ Graduate School of Automotive Engineering, Kookmin Univ., Korea \\ ${ }^{2}$ Computer-aided Mechanical Design Engineering, Daejin Univ., Korea \\ ${ }^{3}$ School of Aerospace, Mechanical and Manufacturing Eng., RMIT Univ., Australia \\ ${ }^{4}$ School of Media and Communication, RMIT Univ., Australia \\ *dsbaik@daejin.ac.kr
}

\begin{abstract}
There are two types of fuel supply method in $C N G$ vehicles. One is premixed ignition and the other is gas-jet ignition. In premixed ignition, the fuel is introduced with intake air so that homogeneous air-fuel mixture may form. The ignitability of this method depends on the global equivalence ratio. In gas-jet ignition, CNG is introduced directly into the engine combustion chamber. The overall mixture is stratified by retarded fuel injection. In this study, a visualization technique was employed to obtain fundamental properties regarding overall mixture formation and combustion characteristics of direct injected CNG fuel inside a constant volume chamber and engine. For gas-jet visualization, Schlieren high speed imaging is used with the effects of ambient pressure and impingement wall on mixture formation being investigated.
\end{abstract}

Keywords: CNG (Compressed Natural Gas), CVC (Constant Volume Chamber), DI (Direct Injection), Visualization, Schlieren Method

\section{Introduction}

With an increase of automobile demands in developing countries and close-to-sole dependency on crude oil based internal combustion (IC) engine fuels, significant petroleum resources have been consumed and this increased consumption of the fossil based fuels has caused the environmental issues of global warming more seriously than ever before. As a result, great needs for highly efficient engines to reduce the amount of fuel consumption and eco-friendly engines to alleviate the greenhouse gas emissions easing the progression of the global warming mechanism are growing tremendously. Until at least 2020, the penetration of alternative fuels in the transportations market will rise significantly due to increasingly stringent emission standards especially for Greenhouse Gases [1]. In an effort to address this seemingly conflicting task, numerous researches with various approaches have been conducted to suggest possible solutions to the issues. Compressed Natural Gas is a good candidate to limit $\mathrm{CO}_{2}$ emissions, because it contains less carbon than other fossil fuels such as gasoline and diesel. The theoretical $\mathrm{CO}_{2}$ emissions using $\mathrm{CNG}$ for the same energy introduced in the combustion chamber are $23 \%$ lower than those using gasoline in stoichiometric conditions. This is due to $\mathrm{CNG}$ 's higher $\mathrm{H} / \mathrm{C}$ (hydrogen over carbon ratio) molecular ratio: close to 4 as compared to approximately 1.8 for gasoline [2]. At present there are two types of combustion method for CNG engines; premixed ignition and gas-jet 
ignition [3]. Recently several researchers mainly focused on concepts based on the lean approach for $\mathrm{CO}_{2}$ emission reduction and increased efficiency thanks to compression ratios higher than those of gasoline engines. Two strategies for mixing were studied: lateral wall guided or central injection $[4,5]$. In both cases, the authors converged on a compression ratio of 13:1. Also, CNG lean-burn approach is adapted to gas engines due to advantages of relatively high combustion efficiency and low nitrogen oxides $\left(\mathrm{NO}_{\mathrm{x}}\right)$ [6]. However, lean-burn CNG combustion poses technical problems, such as ignitability and flame propagation [7]. Such problems are known to cause misfire and incomplete combustion, which set the CNG lean combustion limit and increase toxic emissions such as total hydrocarbon (THC) and carbon monoxide (CO) [8]. Directly injected hydrogen assisted CNG (called HCNG) fuel to achieve a more reliable combustion, low $\mathrm{NO}_{\mathrm{x}}$ emissions, high thermal efficiency and lower hydrocarbon (HC) emissions. By applying hydrogen assisted jet ignition, $\mathrm{HC}$ emissions were reduced by a further 100 ppm without increasing $\mathrm{CO}$ and $\mathrm{NO}_{\mathrm{x}}$ [9-13].

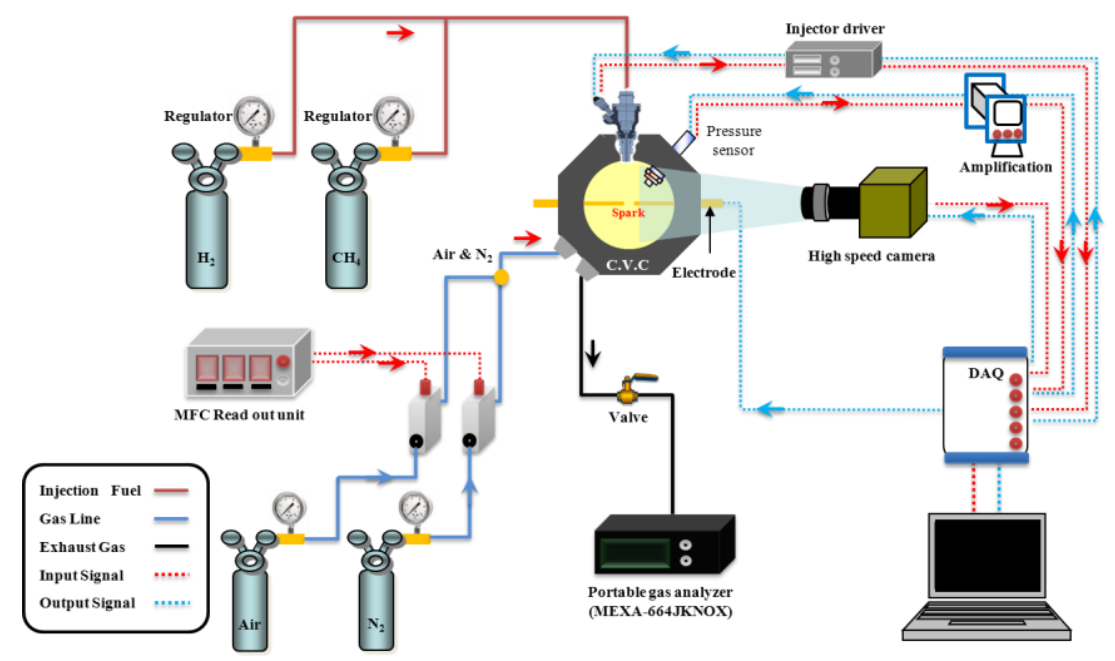

Figure 1. Schematic diagram of experimental apparatus with a constant volume chamber

Table 1. Experimental conditions

\begin{tabular}{l|l}
\hline CVC $(\mathrm{mm})$ & $96 \times 39($ Bore $\times$ Width $)$ \\
\hline Volume $\left(\mathrm{cm}^{3}\right)$ & 282 \\
\hline Fuel Delivery & Direct injection \\
\hline Injection pressure (bar) & 85 \\
\hline Injection duration $(\mathrm{ms})$ & $2.0 \sim 4.5$ \\
\hline Injector & $0.19 \mathrm{~mm}, 6$ hole \\
\hline Fuels $($ vol.\%) & $\mathrm{CNG}\left(\mathrm{CH}_{4} \geq 90 \%\right)$ \\
\hline & Atmospheric condition \\
$\mathrm{P}_{\text {ambient }}$ & 5 bar $\left(\mathrm{P}_{\text {inj }} / \mathrm{P}_{\mathrm{a}}=14.3\right)$ \\
\hline $\mathrm{T}_{\text {ambient }}$ & $10 \mathrm{bar}\left(\mathrm{P}_{\mathrm{inj}} / \mathrm{P}_{\mathrm{a}}=7.8\right)$ \\
\hline
\end{tabular}




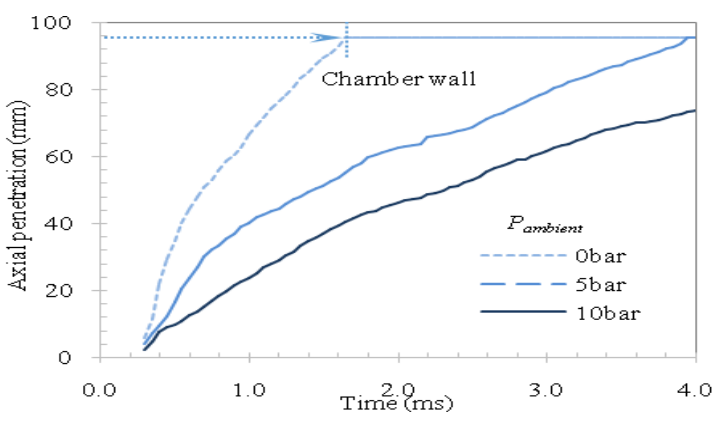

Figure 2. CNG free-jet penetration

\section{Experimental apparatus and procedure}

A constant volume chamber with a bore of $96 \mathrm{~mm}$ and a width of $39 \mathrm{~mm}$ was used to visualize the jet patterns of the CNG from an injector and to analyze the diffusive flame propagations, combustion and emission characteristics. Further details of the experimental conditions are summarized in Table 1 . To reproduce a high pressure conditions prior to fuel injection in the chamber, the chamber was filled with oxygen and nitrogen gases. Concentration of each gas was adjusted by measuring the partial pressure of each gas using a pressure gauge attached to the chamber. As shown in a schematic diagram of the experimental setup (Figure 1), the experimental setup was designed to perform several cases of parametric studies and found to be very practical. A high-speed video camera from Photon (FASTCAM Ultima 512) was used at the speed of 20000 and $30000 \mathrm{fps}$ (frames per second) to visually investigate the gas-jet patterns (light source: LED lamp) and the diffusive flame propagations (no external light source), respectively. CNG is injected under the ambient pressure of $0,5,10 \mathrm{bar}$ (gauge) with the injection pressure of $85 \mathrm{bar}$. The ambient condition inside the CVC was maintained at high pressure similar to the typical conditions of a gasoline engine. After combustion, exhaust emissions were sampled with a portable exhaust gas analyzer (Horiba MEXA554JKNOX) for all parametric studies. Four cartridges of heater were installed at the CVC wall to maintain wall temperature of $80^{\circ} \mathrm{C}$.
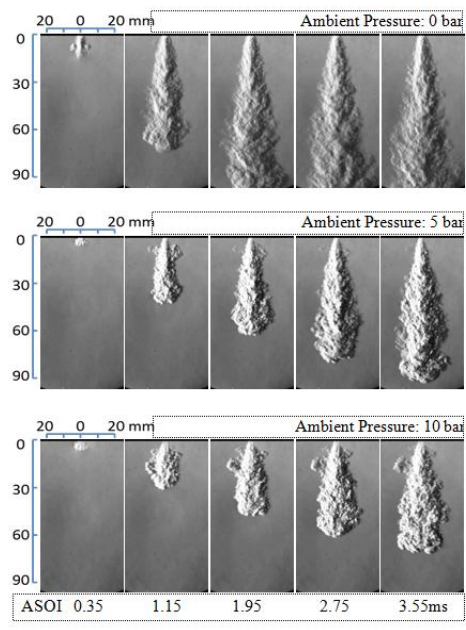

Figure 3. Schlieren images of the transient CNG free jet under different ambient pressure 


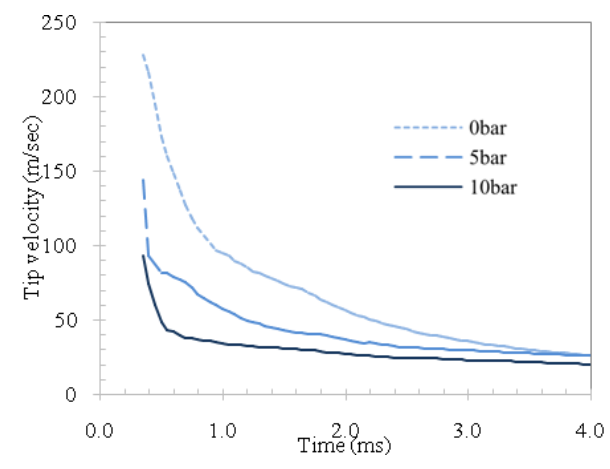

Figure 4. CNG free-jet tip velocity

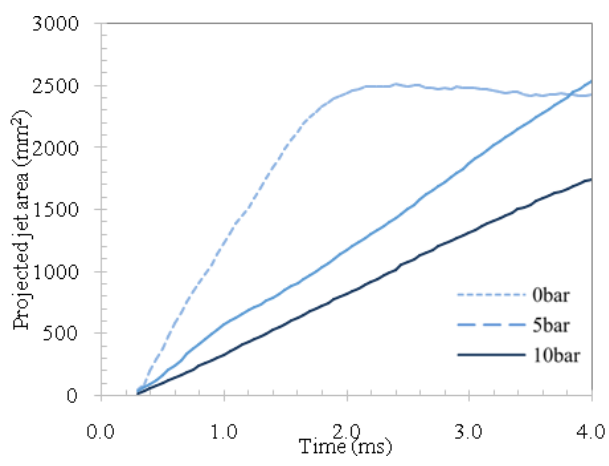

Figure 5. CNG free-jet projected area

\section{Results and discussions}

Figure 3 shows Schlieren images of the transient CNG free jet under different ambient pressure ranging from $0.0 \sim 10$ gauge bar with the injection pressure of 85 gauge bar. Series of photographs were captured in time order from the beginning of injection signal. Based on the qualitative observation of these images, the penetration decreases apparently and the time reaching the CVC wall was delayed as the chamber pressure increases. This is caused by the higher inertia of the fluid elements that the injected fluid must accelerate and push aside [13]. It is same to liquid fuel such as diesel and gasoline, but this phenomenon is far more prominent for the gaseous fuel. Graphs of the jet penetration, velocity, angle and projected area for CNG are plotted in Figure 3-6 based on the images shown in Figure 2. In Figure 2, 4, and 5, it is clear that the ambient pressure increases, jet penetration tend to decrease dramatically. From dimensional analysis, the penetration length $Z_{t}$ for a compressible transient jet is used.

$$
Z_{t}=\Gamma\left(\frac{\dot{M}_{n}}{\rho}\right)^{\frac{1}{4}} t^{\frac{1}{2}}
$$

$$
\begin{aligned}
& M_{n}: \text { Nozzle momentum injection rate } \\
& \rho: \text { Chamber density } \\
& t: \text { Time elapsed from the start of injection } \\
& \Gamma: \text { A function of the above stated ratio } D / Z_{t} \text { (constant) }
\end{aligned}
$$

In this equation, the penetration length is proportional to $\dot{M}_{n} / \rho$. The chamber density $\rho$ is related to $P_{\text {ambien }}$ t by the ideal gas equation. $M_{n}$ is the product of the nozzle mass flow rate $m$ and the nozzle exit velocity $v$ if uniform exit conditions are assumed. Both $M_{n}$ and $v$ are proportional to $P_{\text {injection }}$ and inversely proportional to $P_{\text {ambient }}$ for subsonic conditions. In summary, $M_{n} / \rho$ is proportional to the ratio of $P_{\text {injection }} / P_{\text {ambien }} t$ for both subsonic and choked nozzle flow [14]. In Figure 5, lines of penetration versus the square root of time provide a visual measure of how well the data follows a square root of 
time dependence. It shows the slope of the linear portion of each data set is also different for each condition. In Figure 5, the CNG free-jet tip velocity also tends to decrease dramatically as the ambient pressure increases. Especially, at the beginning of the injection, tip velocity under atmospheric condition is faster over two times than that of less than 10 bar condition. This is due to the differences in both the momentum supplied to the jet and the density of the ambient gas for differing conditions. This means that the CNG jet at the higher ambient pressure condition has a slightly bigger core and less penetration force. At this ambient pressure level, CNG fuel do not have enough penetration forces to collide against with the chamber wall. Figure 6 shows a projected free-jet area. At the atmospheric pressure condition, jet area is larger about 4 times comparing at ambient pressure 10 bar condition. This is because of strong jet penetration even though jet angle is narrower than that of low ambient pressure condition. Figure 6 shows Schlieren images of the transient CNG impingement jet under different ambient pressure ranging from $0 \sim 10$ bar with the injection pressure of $8.5 \mathrm{MPa}$. Also, Figure 7 and 8 show results of projected jet area and radial penetration from the images. Impingement wall is located $30 \mathrm{~mm}$ form the injector tip. After approximately $0.42 \mathrm{~ms}$ from the injection signal, the injected fuel penetration to the wall and impinged on it at atmospheric condition. Ambient pressure increases to 5 and 10bar, gas jet collision interval to the impingement-wall is delayed $0.3 \mathrm{~ms}$ each approximately. Also, two large vortexes on both sides of spray centerline is shown and rotating in the opposite direction. As ambient pressure increases, radial penetration and projected area decrease apparently.

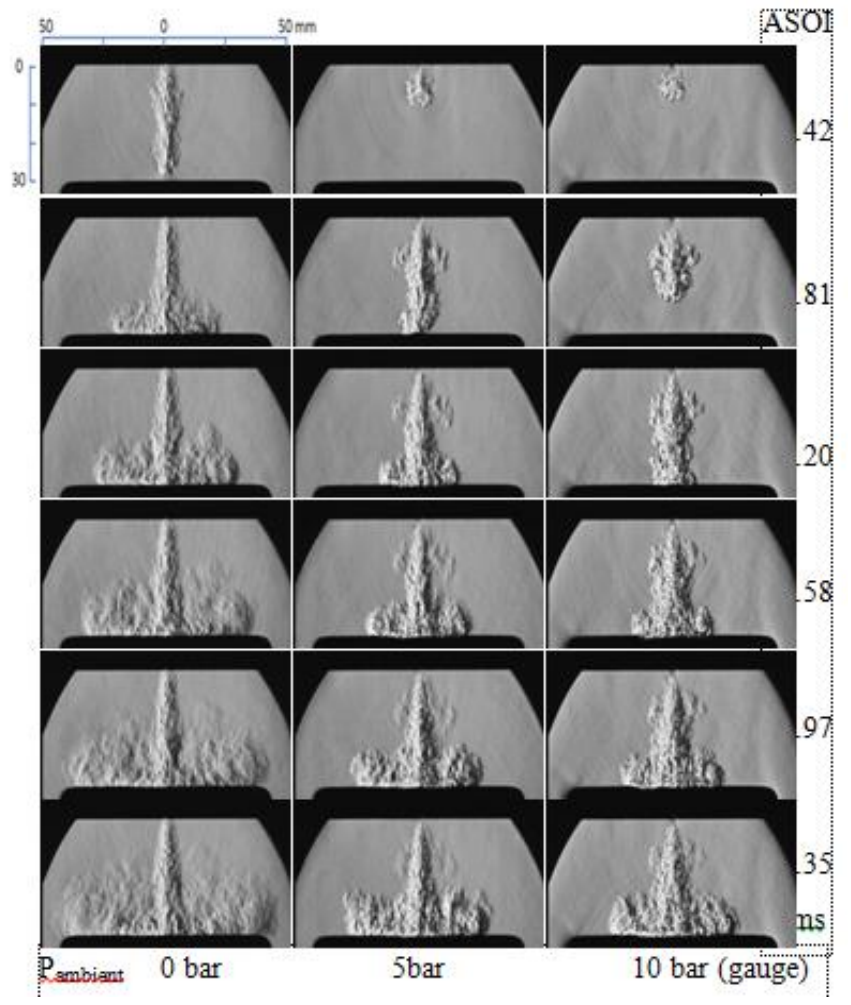

Figure 6. Schlierenimages of the transient CNG impingement jet under different ambient pressure $\left(P_{\text {inj }}: 85\right.$ bar, $\left.T_{\text {ambient }}: 20^{\circ} \mathrm{C}\right)$ 


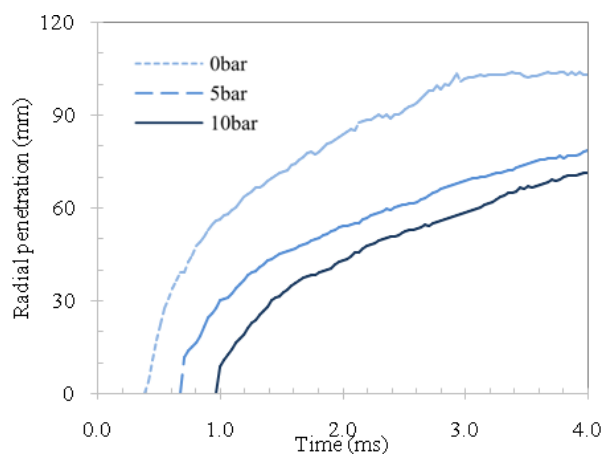

Figure 7. CNG Radial penetration

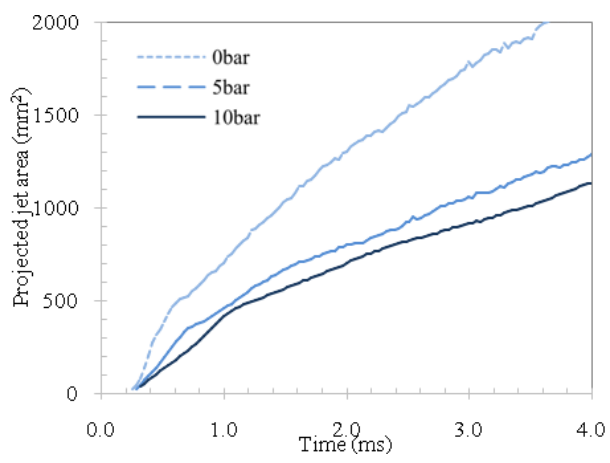

Figure 8. CNG Projected area

\section{Conclusion}

A major challenge for a direct injection engine is the optimization of mixture formation. The jet patterns and combustion characteristics of CNG fuel was investigated in a constant volume chamber. Based on the observation of the qualitative cinematographic visualization for the characteristics of the jet pattern, Schlieren images of CNG free jet are captured under different ambient pressures with injection pressure 85 gauge bar. Jet formations such as its axial and radial penetration distance, tip velocity in terms of time are secured quantitatively. CNG free jet angles with respect to ambient pressure are obtained as well. It is expected that this investigation will be helpful in understanding and improving the directly injected CNG engine and combustion when a directly injection system is used.

\section{Acknowledgements}

This work was supported by the National Research Foundation of Korea Grant funded by the Korean Government (NRF-2012-2012S1A2A1A01028860)

\section{References}

[1] H. M. Cho and B. Q. He, "Spark ignition natural gas engines", Energy Conversion and management, vol. 48, (2007), pp. 608-618.

[2] R. Tilagone, S. Venturi and G. Monnier, "Natural gas - an environmentally friendly fuel for urban vehicles: the SMART demonstrator approach", Oil and Gas Science and Technology, vol. 61, (2006), pp. 155-164. 
[3] M. Ali, Y. Kidoguchi, Y. Oka and T. Kaida, "Improvement of combustion of CNG engine using CNG direct injection and gas-jet ignition method", SAE Paper No. 2011-01-1994, (2011).

[4] S. Taniguchi, Y. Tsukasaki and A. Yasuda, "Study of compressed natural gas injection engine", FISITA paper No. F2006P089, (2006).

[5] M. Baratta, A. E. Catania, E. Spessa, L. Herrmann and K. Roessler, "Multi-dimensional modelling of direct natural gas injection and mixture formation in a stratified-charge SI engine with centrally mounted injector", SAE Int. J. of Engines, vol. 1, (2008), pp. 607-626.

[6] Z. Huang, S. Shiga, T. Ueda, H. Nakamura,T. Ishima,T. Obokata, M. Tsue and M. Kono, "Combustion characteristics of natural-gas direct-injection combustion under various fuel injection timings", Proc. of the IMechE, vol. 217, no. 5, (2003), pp. 393-401.

[7] Y. Kidoguchi, S. Masaaki, U. Hiromitsu and K. Miwa, "A fundamental study on improvement of ignitability and combustion stability of CNG jet", Trans. of JSAE, vol. 36, no. 1, pp. 15-20.

[8] R. D. Nine, N. N. Clark, B. E. Mace and L. ElGazzar, "Hydrocarbon speciation of a lean burn spark ignited engine", SAE Paper No. 972971.

[9] E. W. Deanna and C. W. Harry, "Direct injection compressed natural gas combustion and visualization", SAE Paper No. 2000-01-1838, (2000).

[10] S. Riccardo,W. Thomas, M. Nicholas, S. Victor and K. Sebastian, "Mixture formation in direct injection hydrogen engines: CFD and optical analysis of single and multi-hole nozzles", SAE Paper No. 2011-24-0096, (2011).

[11] S. Turns, “An Introduction to Combustion”, 2nd ed. McGraw-Hill, New York, (1995).

[12] L. Johansen, E. Sienes and P. Dahlander, "Analysis of transient compressible gas jets using high speed Schlieren imaging”, SAE Paper No. 2013-01-0871, (2013).

[13] S. W. Lee, D. S. Baik, T. Rogers and P. Petersen, "Characteristics of CNG fuel engine", Proceedings of International Workshop on Bioscience and Medical Research, (2013) December 11-13; Jeju Island, Korea.

\section{Authors}

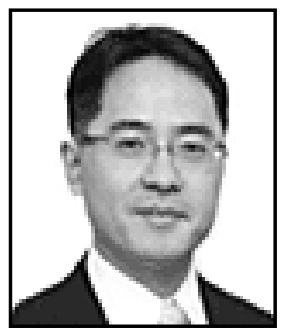

\section{Seang-Wock Lee}

Prof. Kookmin University

$\mathrm{Ph}$. D. Waseda University

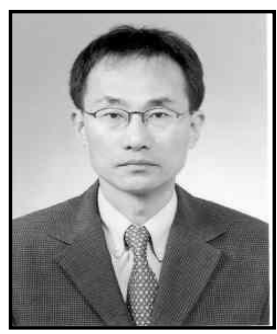

\section{Doo-Sung Baik}

Prof. Daejin University

Ph.D. Wichita State University 
International Journal of Bio-Science and Bio-Technology Vol.6, No.2 (2014) 